\title{
APPLICATIONS OF TERRESTRIAL LASER SCANNING AND GIS IN FOREST INVENTORY
}

\author{
Cătălina Cristea ${ }^{\mathbf{a}}$, Andreea Florina Jocea ${ }^{\mathbf{b}, *}$ \\ a Technical University of Civil Engineering of Bucharest, Faculty of Geodesy, Department of Geodesy and Photogrammetry, Lacul \\ Tei Blvd., no. 122-124, sector 2, postal code 020396, Bucharest, Romania, e-mail: cristea catalina@ymail.com \\ ${ }^{\mathrm{b}}$ Technical University of Civil Engineering of Bucharest, Faculty of Geodesy, Department of Surveying and Cadastre, Lacul Tei \\ Blvd., no. 122-124, sector 2, postal code 020396, Bucharest, Romania
}

Received: 10.09.2015 / Accepted: 10.10.2015 / Revised: 13.11.2015 / Available online: 15.12.2015

DOI: $10.1515 /$ jaes-2015-0016

KEY WORDS: point cloud, terrestrial laser scanner, GIS, forest inventory

\begin{abstract}
:
During last years the need of knowing the forest in its various aspects, quantitative and qualitative, has enabled the appearance of a new technique forestry geomatics. Named as "the science of future" this technique integrates multiple technologies such as Remote Sensing, Airborne Photogrammetry, LIDAR, Geographic Information System (GIS), Global Positioning Systems (GPS) or classical geodetic technology for data acquisition, data processing, data analysis and data management. The purpose is to provide specific information regarding the evaluation natural forestry resources. In this paper will be presented the utilization of terrestrial 3D laser scanner and GIS technologies in forestry inventory.
\end{abstract}

\section{INTRODUCTION}

Over the past decades, a concern from the specialists in forestry part regarding the management of forest resources could have been noticed. This concern has generated - what in the literature is called - the sustainable management of the forest resources (Birjaru, 2011).

Sustainable management aims forest fund knowledge, from two points of view: spatial position, stretch and textual - state, species, and structure. Wanting to have a complete spatial representation on plans and maps of forest resources, over the years, the measurements were carried out using the traditional technology (compasses, tachometric) which is accurate but time and financial resources consuming. Nowadays for this purpose it is used the modern means of inventory aerial photogrammetry, Remote Sensing, Airborne Laser Scanning, Terrestrial Laser Scanning etc.

The airborne scanning devices that use complex data acquisition methods such as LiDAR ((Light Detection And Ranging), can be used precisely for land usage or land monitoring purposes. LiDAR technology is complex one, being based on laser measurement techniques associated with a high precision GPS and an inertial measurement unit IMU (Inertial Measurement Unit), assembled all together on an aerial platform. Therefore the data collected using this kind of aerial instrument is a complex one, requiring a high precision method for processing. The main advantage of the LiDAR technology is the fact that the laser beam can penetrate through vegetation, giving answers regarding either the surface items or the not so visible ones.

\footnotetext{
* Corresponding author: e-mail: ajocea@yahoo.com
} 
This is the reason for which the LiDAR data can be used in a Geographic Information Systems (GIS) in order to study forestry maters such as canopy management, forest management, drainage plans or biomass management.

Almost the same amount of data as in the LiDAR case can be obtained by using a Terrestrial Laser Scanner.

Taking into account the current specialized literature, the TLS has been shown to be a promising technique for forest-related studies. Numerous tree characteristics can be determined using measurements from TLS data. Until present have been proposed many TLS methods in order to achieve data, but unfortunately the feasibility of applying TLS in forest inventories is still unclear. Also it is considered that TLS technique has some disadvantages such as the fault of automation of data processing (the algorithms and methods for data handling and parameters extraction) and the relatively high cost of the equipment. The main advantage of using TLS in forest inventory is its capability to describe the forest in detail (Liang, 2013).

TLS techniques imply lateral data acquisition, which is why the main question that needed an answer was "Can TLS data be combined with GIS techniques for forestry matters in the same manner LiDAR data is"?

On international level, the use of GIS is in continuous increase. We are no longer talking about desktop applications but about web based or cloud applications, which can be accessed simultaneous by multiple users. Created at first as a solution for specific simple matters, one can see at the present time a continuous diversification on theoretical and practical GIS levels, when it comes either to data management issues or development problems. It is also known the fact that the GIS concepts embody different data acquisition methods, storing methods or visualization matters all of these being used for single or for multiple tasks.

The main objective of the paper is to demonstrate the practicability and the potential/capabilities of using TLS and GIS technologies in forest assessment.

\section{BASIC CONCEPT}

\subsection{Terrestrial Laser Scanning (TLS)}

In a world information-dominated, the three dimensional spatial data achievement, its analysis and fast accessibility to users are important issues. This problem is investigated by a multitude of research discipline such as geodesy, architecture, computer vision, engineering, infrastructure planning and robotics. Also, in the last years there are many demands for detailed 3D spatial data coming from the part of industrial and private users (Paffenholz, 2012).

Representative applications are as-built and cultural heritage documentation, the generation of 3D city models, civil engineering and forensic investigations (Badea et. al, 2009; Jocea et al., 2013).

3D spatial data for mapping purposes is frequently acquired by both, digital cameras and laser range sensors, which are generally called Light Detection and Ranging (LiDAR) sensors or laser scanners (Mikhail et al., 2001; Vosselman and Maas, 2010).

The determination of $3 \mathrm{D}$ object point coordinates with cameras involves multiple images (Luhmann et al., 2006). In the case of laser scanners, the distance between the laser scanner and an object is recorded by a laser beam, and simultaneously, the horizontal and vertical angles towards the object are acquired (Paffenholz, 2012; Jocea et al., 2015). Information about the scanning mechanism and measuring technique are presented in (Reshetyuk, 2009).

The main advantages of TLS over digital cameras is the fact that the first ones provide a dense object points in a 3D space with millimetres precision with high speed (a few minutes of acquisition time), the 3D coordinates being achieved without post processing of resection by multiple images in order to obtain the depth information of objects (Mikhail et al., 2001; Vosselman and Maas, 2010).

In the recent years, TLS has become a promising technique for forest field inventory. Several research studies aim to outline the advantage that TLS is offering in forest field inventory, which lies in its capacity to document the forest in details (Erikson and Karin, 2003; Simonse et al., 2003; Watt et al., 2003; Aschoff and Spiecker, 2004; Haala et al., 2004; Hopkinson et al., 2004; Thies and Spiecker, 2004; Danson et al., 2007; Kiraly and Brolly, 2008; Seidel, 2011; Liang, 2013; Jocea and Cristea, 2015). It is considered that TLS is providing data which can be post processed using different techniques, offering new opportunities to increase the forest sustainable management. 
Even so, after a decade of studies, TLS has not yet been accepted as an operational tool in forest inventories. Its application is hampered mainly by difficulties in the automation of the point cloud processing that provides convincing measurement results of the most important forest inventory parameters (Liang, 2013).

\subsection{Geographic Information Systems (GIS)}

Geographical Information Systems is an information technology that has been used in public policymaking for environmental and forest planning and decision-making over the past decades (Bassole et al., 2001).

Nowadays, GIS is a powerful tool which involves spatial analysis and modelling using relational database management, interpolation, graphic algorithms and network analysis principles.

The ability of GIS to handle and analyze spatial data is usually seen as the characteristic that most distinguishes them from other information, computer aided design, and map production, systems. Spatial data sets provide two types of information: data describing the specific locations of objects in space (and their topological relationships), the so-called positional and topological data, and data describing non-spatial attributes of the objects recorded the attribute or thematic data (Fischer et al., 2005).

Forest management has become more complex as there are now multiple objectives to attain, as well as multiple criteria and constraints to address (Warnecke et al., 2002). GIS helps the forestry specialists to manage efficiently forest assignment and reduce costs, being an appropriate tool, providing data coming from different sources for an intelligent development (Tasoulas et al., 2013).

\subsection{Integration of TLS and GIS techniques for forest inventory}

It is widely recognized that GIS have four basic functions related to spatial data (Goodchild, 1987; Anselin and Getis, 1993; Fischer and Nijkamp, 1992; Fischer et al., 2005):

1. Data input (data model, data measurement).

2. Data storage, recovery and database management.

3. Data analysis (data manipulation, exploration and confirmation).

4. Output (display and product generation).

According to Anselin and Getis (1993) the relations between these four basic functions can be shown in figure 1:

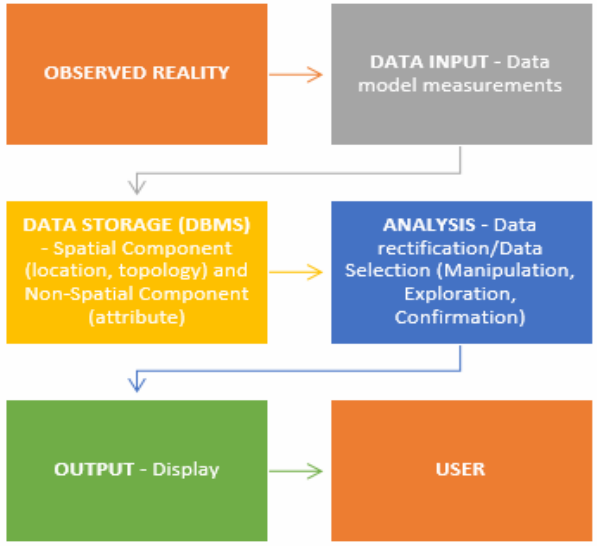

Figure 1. The relation between four basic functions (adapted after Anselin and Getis, 1993)

In spatial data processing environment there is a major problem which consist in data integration, referring to the method of making data sets compatible with each other.

Data incompatibilities may be caused by the utilisation of different spatial reference system, different degrees of generalisation, location errors etc. (Fischer et al., 2005).

This is the reason for which we had to pay attention to the extensions necessary for implement particular tasks.

Our goal in this paper is to show that the ArcGIS software provided by ESRI enables post processing of data achieved using TLS, provides the possibilities of creating DTMs and is suitable to analyze the structure of the forest. In order to accomplish these tasks it is necessary to use 3D Analyst extension. Taking a look into the software we can observe that all the importing extensions of regarding point cloud data is referred to LiDAR and non to TLS. Anyway, for TLS data integration in ArcGIS software we can use the TXT file tool (Walter, 2010).

\section{STUDY CASE}

\subsection{Research area description}

The experimental area is located in Baneasa Forest near Bucharest, Romania (figure 2). The whole forest has about 900 ha. The test area consisted in a $256 \mathrm{sqm}$ and it was acquired in May 2014.

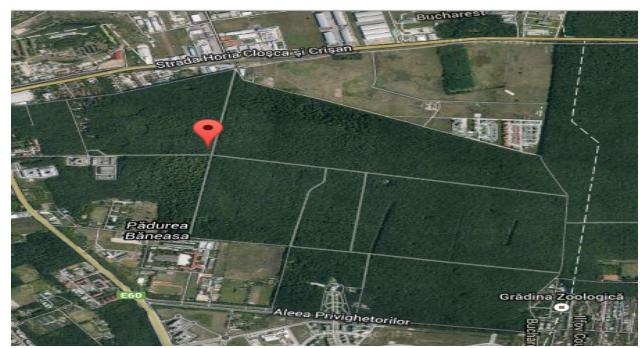

Figure 2. The location of the test area (Jocea and Cristea, 2015) 


\subsection{Data acquisition and processing}

Both TLS and LiDAR scanning processes have as result a large information file with points on certain spatial coordinates called point cloud.

The test point cloud that we used in our study was obtained using TLS procedure (figure 4). For this, a Leica ScanStation 2 (table 1) was used to acquire the assets. The scanned data had been stored and processed at first using the related software Leica Cyclone and with ArcGIS platform - as GIS tool provider.

\begin{tabular}{|l|l|}
\hline Leica ScanStation 2 & \\
\hline $\begin{array}{l}\text { Distance measurement } \\
\text { principle }\end{array}$ & Time of Flight (Pulsed) \\
\hline User interface & Notebook/Tablet PC \\
\hline Accuracy position & $6 \mathrm{~mm}$ at $1 \mathrm{~m}-50 \mathrm{~m}$ range, one sigma \\
\hline Accuracy distance & $4 \mathrm{~mm}$ at $1 \mathrm{~m}-50 \mathrm{~m}$ range, one sigma \\
\hline Field of view & $360^{\circ}$ (horizontal) X $270^{\circ}$ (vertical) \\
\hline Range & $300 \mathrm{~m}$ at $90 \% ; 134 \mathrm{~m}$ at $18 \%$ albedo \\
\hline Scan rate & Up to 50000 points $/ \mathrm{sec}$ \\
\hline
\end{tabular}

Table 1. Characteristics of Leica ScanStation 2 laser scanner (Leica, 2015; adapted after Lee et al., 2013)

The workflow of the 3D point cloud data can be summarizing in figure 3.

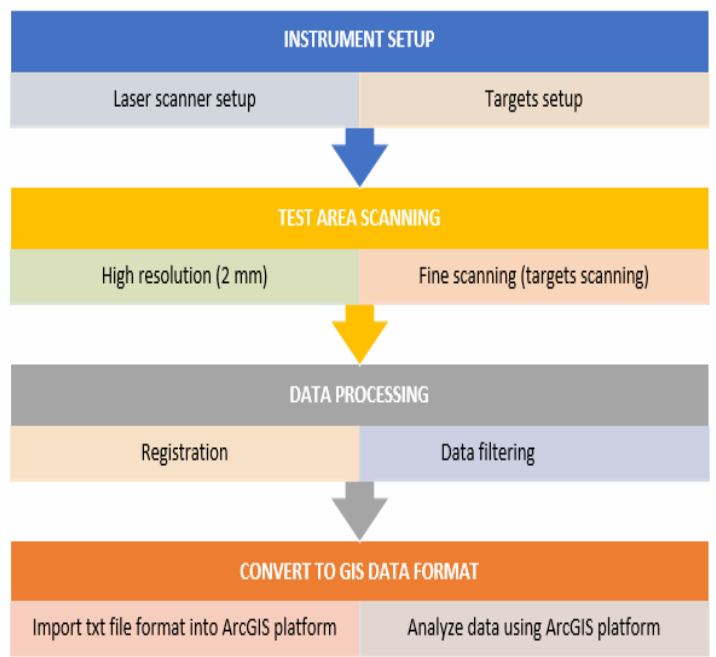

Figure 3. The 3D data processing workflow (adapted after Lee et al., 2013)

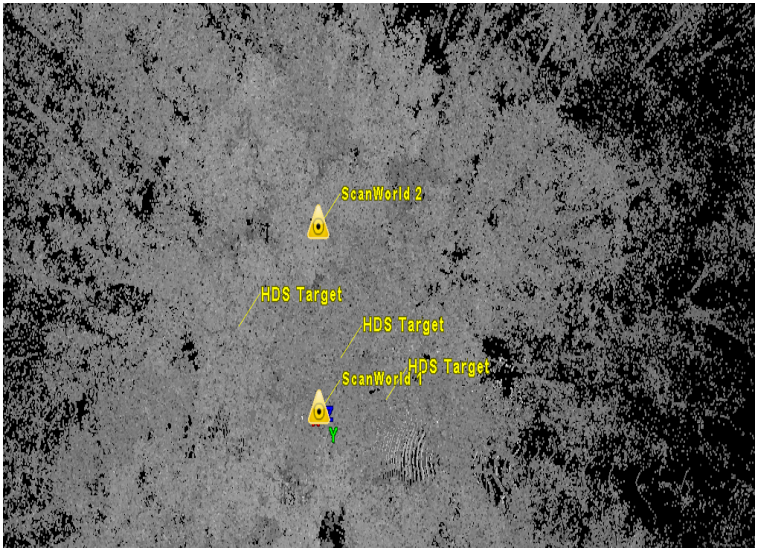

Figure 4. Leica ScanStation 2 scanner and targets position (Jocea and Cristea, 2015)

The large amount of data require a special structure that is able to work as fast as needed with both 3D representations of the scanned area or object and with multipoint data. The tool that accomplishes both of the matters, updating the fields as fast as possible and allowing the user to interact with the data, was the Geodatabase Terrain that could keep the data in .XYZ format and the terrain representation, as well. In this manner miscellaneous data can also be blended into one single surface.

In the TLS and LiDAR case the important surfaces are the DSM and the DEM. The DEM represents a surface that resulted out of the beams reflected from the ground level. It is used by forestry engineers to project different routine activities. The DSM, the model obtained from the beams reflected by coverages, is mostly used to obtain information about the structure of the forest in itself (Jocea and Cristea, 2015).

Both DEM and DSM can be determined easily from LiDAR data since the beams sent from the aerial platform pass through to the ground and also give the model of the canopy. These models are not so easy to get from the TLS data, since the point cloud is obtained from one side of the obstacle, not from above. In this case the DEMs are obtained from the lows points, and the DSMs from the highest points. Therefore, we had to separate the point cloud into two smaller point clouds, one gathering points with the lowest elevations, another with the highest elevations.

As in the LiDAR case, the low elevation point clouds had been used in order to create the DEM for the study plot, while the DSM had been created using the high elevation point cloud.

Both DSM (figure 5) and DEM (figure 6) will be represented in ArcGIS as raster data, for easier further analysis use. It is important to choose the cell size the best suits your interests. If you choose a cell size too 
small there might be too many areas in the raster with no data available, so blanks or white spaces. On the other hand, a too large cell will lead to a raster with not so many details. The cell size should be chosen in accordance with the average point spacing, which can be obtained automatically in ArcGIS, by using the Point File Information Tool (Jocea and Cristea, 2015).

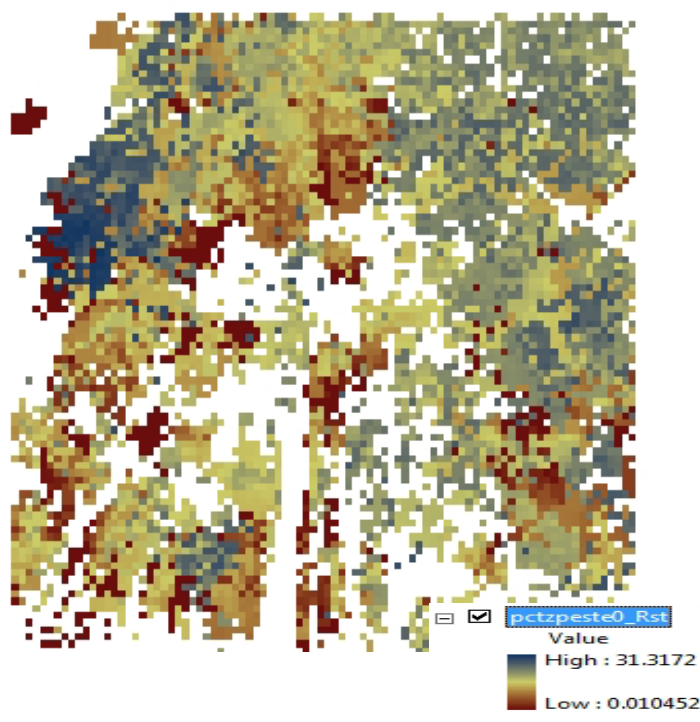

Figure 5. DSM representation (Jocea and Cristea, 2015)

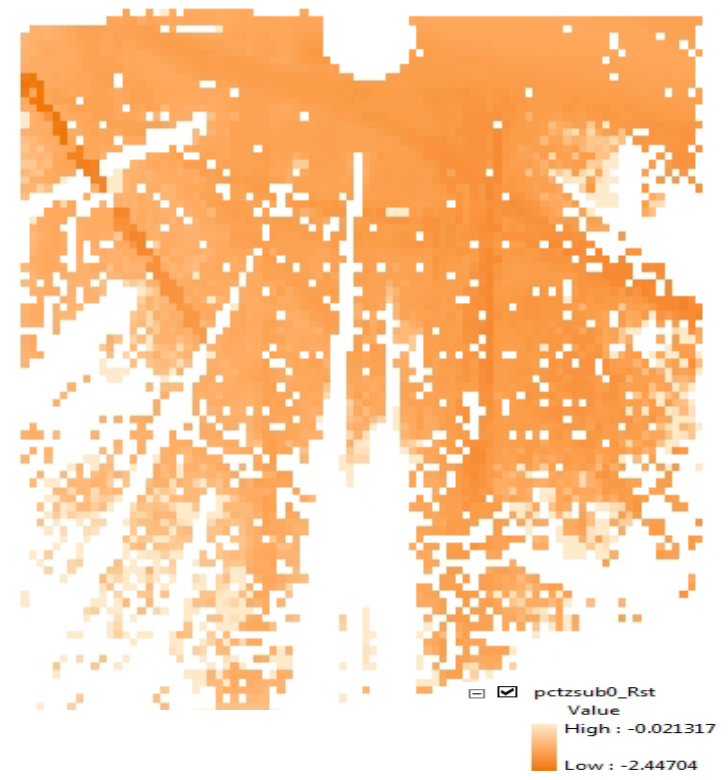

Figure 6. DEM representation (Jocea and Cristea, 2015)

From the DSM and the DEM, which are actually the high-elevation profile and the lowest elevation profile, we can determine the height of the trees (figure 7). The result will be stocked in a raster file and will be obtained automatically by applying a simple math operation, called raster calculus method: DSM Minus DEM (Jocea and Cristea, 2015).

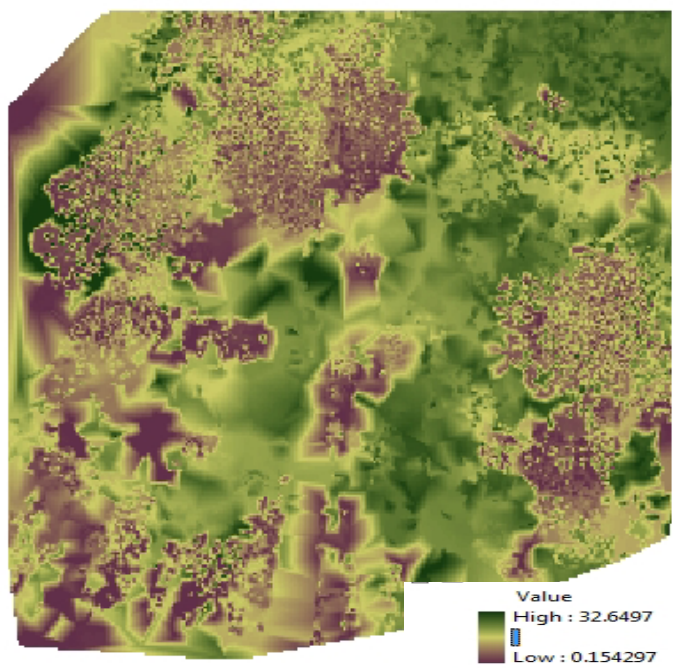

Figure 7. The trees height rate (Jocea and Cristea, 2015)

By using this raster, one can determine the height at a certain point. But, at the same time, by using GIS tools, the height of the trees in itself can be determined. This is a semi-automated operation sequence. At first it has to be created in the geodatabase an empty shapefile that must have as entities polygons. This shapefile will be completed by an ArcGIS user. But before starting to complete the trees shapefile, the user has to make a selection of the points with value around zero.

In the TLS case, the zero value means the height of the instrument at the moment of scanning. By creating the selection, the number of points will be smaller, and the profile of the trees will be easier seen, as in figure 8 .

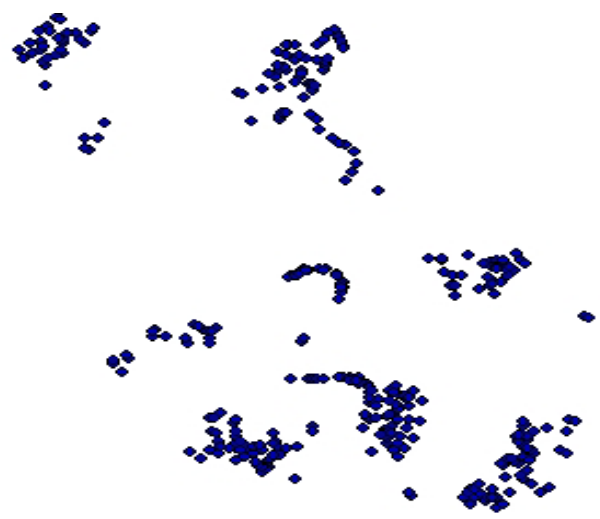

Figure 8 . The profile of the trees

As an observation we can say that in order to determine a precise diameter of the trees, the entire test area should have been scanned all around. For the test area, with only two station points, we can envision what the real diameter is. We want to get as many information as 
possible, that is why from the amount of points we will select, once again, only the ones that are inside the polygons that determine the trees diameter. In this way we will have both the diameter and height of the tree, being able to compute the volume of timber that might came out (figure 9). By using another extension of ArcGIS, ArcScene, we could create the elevation of the trees, by using the $\mathrm{Z}$ coordinate, from the .xyz file.

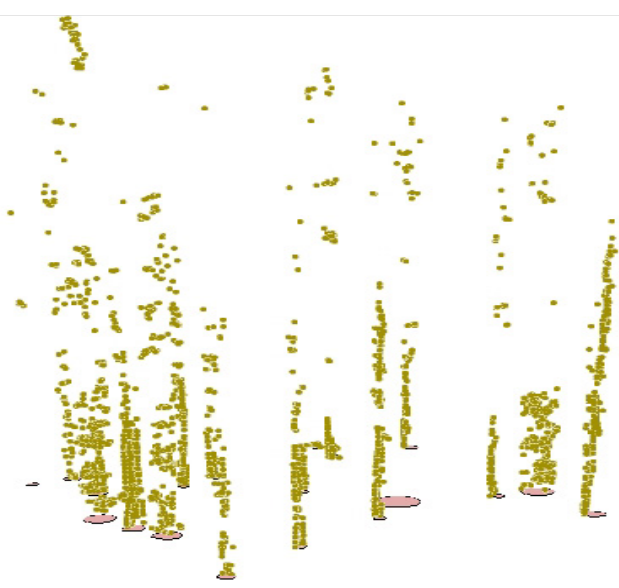

Figure 9. The volume of timber

After using this semi-automatic algorithm for determining the volume of timber we came to the conclusion that for this matter GIS is not the most easy tool to apply or suitable solution.

The LiDAR collected data is in many cases used to determine which the coverage of the land is. Also, in many cases it is easy to determine the species of the forest trees. By using accurate scanners and low profile platforms the specialists determined profiles for each tree type, as shown in figure 10 .
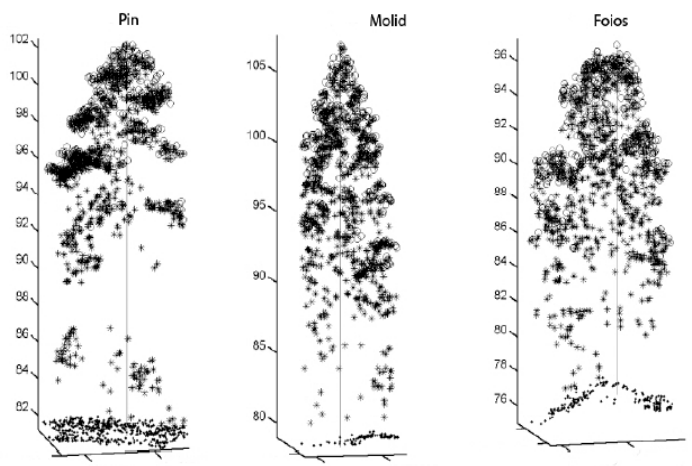

Figure 10. The species of the forest tree (Birjaru, 2011)

If we take into account their description, the test area is a part of a deciduous, thing that is completely correct. In order to determine the type of the trees, the user must inspect by the point cloud himself (figure 11).

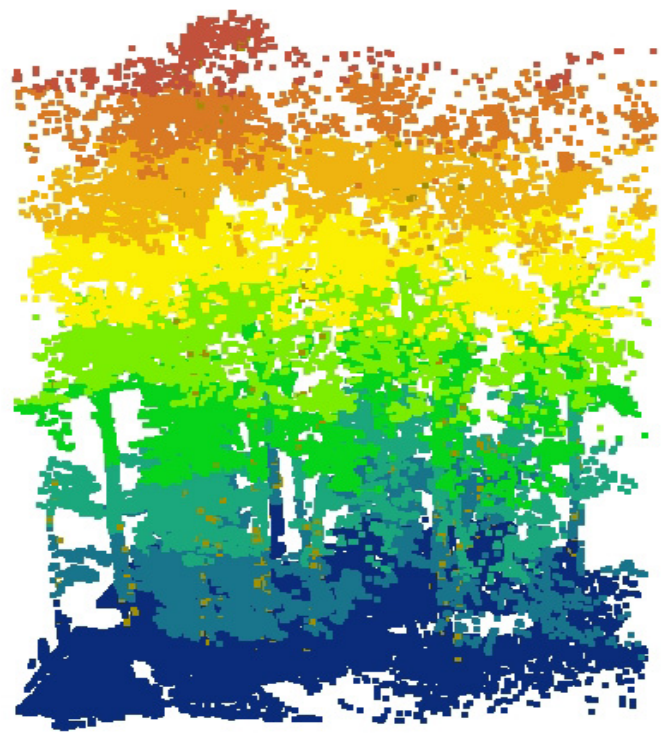

Figure 11. The type of the trees using TLS

At last, one of the most important forestry applications is the determination of the biomass density, which indicates the rate of tree growth from a certain area and the soil quality.

Unfortunately, TLS cannot register data that could help the user associate the vegetation to a certain class, as it is possible using the LiDAR data. But, this type of operations can be attached to a fully automatic cycle. That is why we created a model using the attached application of ArcGIS called Model Builder, which is a very intuitive resource. The process required several intermediate steps, starting from the two DEM and DSM raster created from the point cloud, detailed in the next table.

\begin{tabular}{|c|c|c|}
\hline $\begin{array}{l}\text { Tool } \\
\text { name }\end{array}$ & Explanation & Observations \\
\hline Is Null & $\begin{array}{l}\text { All cells with no data or } \\
\text { null values will be given } 0 \\
\text { value, meaning there is no } \\
\text { vegetation. }\end{array}$ & $\begin{array}{l}1 \text { is assigned to cells } \\
\text { with data, that are not } \\
\text { null }\end{array}$ \\
\hline Con & $\begin{array}{l}\text { Evaluates each cell of the } \\
\text { input raster and verifies if } \\
\text { it is } 0 \text {, value accepted as } \\
\text { true. }\end{array}$ & $\begin{array}{l}\text { If a value of } 1 \text { is } \\
\text { encountered, the tool } \\
\text { pulls the value from the } \\
\text { original raster file. }\end{array}$ \\
\hline Plus & Merges two raster together & \\
\hline Float & $\begin{array}{l}\text { So that the density raster } \\
\text { show a true representation, } \\
\text { one of the raster must have } \\
\text { float values }\end{array}$ & \\
\hline Divide & Calculates canopy density & $\begin{array}{l}\text { Has values between } 0 \\
\text { and } 1\end{array}$ \\
\hline
\end{tabular}

Table 2. The process of creating a Model Builder

After using all of these tools, the result will be also a raster, with values between 0 and 1 . The model created using Model Builder has the advantage that can be used by countless users. The input data can be considered 
parameter, meaning that every user can run the model for his or her own data. The model is shown in figure 12 .

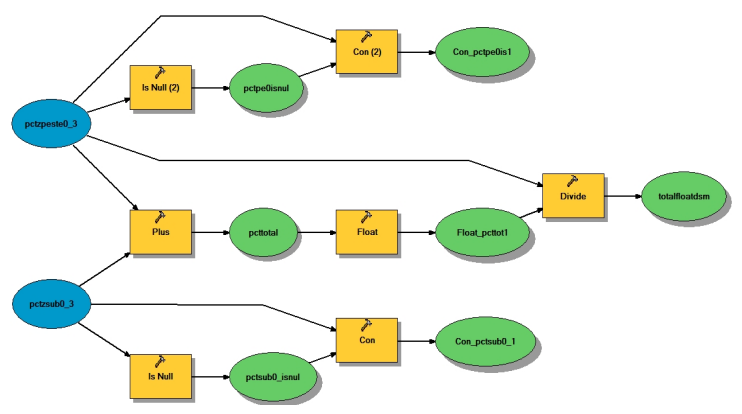

Figure 12. The Model Builder schema

\section{CONCLUSIONS}

For a sustainable forest management is essential a better knowledge of the forest as spatial and textual data. Today, the needed information can be acquired using modern technology such as LiDAR, Remote Sensing, GIS, TLS etc.

As shown above TLS is used in forestry inventory since relatively recent years. The problem of applying TLS for forestry is carried out in countries, where the forestry has a significant value from economic point of view, such as: Germany, United States of America, Canada or Nordic Countries (Walter, 2010).

The present study case aim to demonstrate that the TLS technology can be used as a tool, which can provide data that can be manipulated and interpreted into a GIS environment in order to obtain the quality requirements specified into the technical norms.

\section{REFERENCES}

Anselin, L., Getis A. (1993). Spatial statistical analysis and geographic information systems. In Fischer, M.M. and Nijkamp, P. (Eds) Geographic Information Systems, Spatial Modelling, and Policy Evaluation, pp. 35-49. Berlin: Springer-Verlag.

Aschoff, T., Spiecker, H., 2004. Algorithms for the automatic detection of trees in laser scanner data. In: International Archives of Photogrammetry, Remote Sensing and Spatial Information Sciences 36, pp. 71-74.

Badea, D., Jocea, A. F., Negrilă A., Coşarcă, C., 2009. 3D City modelling by combination of Terrestrial Laser Scanning data and images. In RevCAD - Journal of Geodesy and Cadastre, No. 9, pg. 309-318, Aeternitas Publishing House, Alba Iulia, Romania.
Bassole, A., Brunner, J., Tunstall, D., 2001. GIS: Supporting Environmental Planning and Management in West Africa. World Resources Institute, London, United Kingdom.

Birjaru, C., 2011. Cercetări privind utilizarea tehnologiei LiDAR în lucrările de silvicultură (Study regarding the use of LiDAR technology in forestry), Summary of $\mathrm{PhD}$ Theses, Brasov, Romania.

Danson, F.M., Hetherington, D., Morsdorf, F., Koetz, B., Allgower, B., 2007. Forest canopy gap fraction from terrestrial laser scanning. In IEEE Geoscience and Remote Sensing Letters 4, pp. $157-160$.

Erikson, M., Karin, V., 2003. Finding tree-stems in laser range images of young mixed stands to perform selective cleaning. In: Proceedings of the ScandLaser Scientific Workshop on Airborne Laser Scanning of Forest, pp. 244-250.

Fischer, M., Scholten, H., Unwin, D., 2005. Spatial Analytical Perspectives on GIS, GISdata 4. Taylor \& Francis e-library, United Kingdom.

Fischer, M.M., Nijkamp, P., 1992. Geographic information systems and spatialanalysis. In: The Annals of Regional Science, 26 (1), pp. 3-17.

Goodchild, M., 1987. A spatial analytical perspective on geographical information systems. In: International Journal of Geographical Information Systems, 1 (4), pp 327-334.

Haala, N., Reulke, R., Thies, M., Aschoff, T., 2004. Combination of terrestrial laser scanning with high resolution panoramic images for investigations in forest applications and tree species recognition. In: International Archives of Photogrammetry, Remote Sensing and Spatial Information Sciences 34, p.4.

Hopkinson, C., Chasmer, L., Young-Pow, C., Treitz, P., 2004. Assessing forest metrics with a ground-based scanning lidar. In: Canadian Journal of Forest Research 34, pp. 573-583

Jocea A. F., Călin, A., Plopeanu, M., Dumitru, P., Bădescu, O., 2013. Static Terrestrial 3D Laser Scanning applications in Civil Engineering Projects. In SGEM2013 Conference Proceedings, Vol. 2, pp 413 - 420, Varna, Bulgaria.

Jocea, A. F., Crăciun, E.G., Anton, A., 2015. Approximation of scours using terrestrial 3D laser scanning. In: Journal of Applied Engineering Sciences, Vol 5 (18), Issue 1, University of Oradea Publishing House, Oradea, Romania.

Jocea, A. F., Cristea, C., 2015. Terrestrial Laser Scanning and GIS methods for Forestry Applications. In: Proceedings of Biennial International Symposium „Forest and Sustainable Development", Transilvania University Press, Braşov, Romania pp $301-307$.

Kirally, G., Brolly, G., 2008. Modelling single trees from terrestrial laser scanning data in forest reserve. In: The Photogrammetric Journal of Finland, Vol. 21, No. 1, pp. 37-50. 
Lee, S. Y., Majid, Z., Setan, H., 2013. 3D data acquisition for indoor assets using Terrestrial Laser Scanning. In: ISPRS Annals of the Photogrammetry, Remote Sensing and Spatial Information Sciences, Volume II-2/W1, ISPRS 8th 3DGeoInfo Conference \& WG II/2 Workshop, 27 - 29 November 2013, Istanbul, Turkey.

Leica, 2013. http://hds.leica-

geosystems.com/downloads 123/hds/hds/ScanStation/broc hures-atasheet/Leica_ScanStation\%202_datasheet_en.pdf (accessed September 2013).

Liang, X., 2013. Feasibility of Terrestrial Laser Scanning for Plotwise Forest Inventories, Summary of PhD Theses, Espoo, Finland.

Luhmann, T., Robson, S., Kyle, S., 2006. Close range photogrammetry: Principles, methods and applications. Whittles Publishing, Dunbeath, United Kingdom.

Mikhail, E. M., Bethel, J. S., McGlone, J. C., 2001. Introduction to modern photogrammetry. Wiley, New York, USA.

Paffenholz, J. A., 2012. Direct geo-referencing of 3D point clouds with $3 \mathrm{D}$ positioning sensors, Summary of PhD Theses, Hannover, Germany.

Reshetyuk, Y., 2009. Self-calibration and direct georeferencing in terrestrial laser scanning. Doctoral Thesis in Infrastructure, Geodesy, Royal Institute of Technology (KTH), Department of Transport and Economics, Division of Geodesy, Stockholm, Sweden.

Seidel, D., 2011. Terrestrial laser scanning. Applications in forest ecological research. In: Biodiversity and Ecology, Serie B, Volume 6, Göttingen Centre for Biodiversity and Ecology, Germany.

Simonse, M., Aschoff, T., Spiecker, H., Thies, M., 2003. Automatic determination of forest inventory parameters using terrestrial laserscanning. In: Proceedings of the ScandLaser Scientific Workshop on Airborne Laser Scanning of Forests, pp. 252-258.

Tasoulas, E., Varras, G., Tsirogiannis, I., Myriounis, C., 2013. Development of a GIS Application for Urban Forestry Management Planning. In: Procedia Technology, 8, Published by Elsevier Ltd., pp 70-80.

Thies, M., Spiecker, H., 2004. Evaluation and future prospects of terrestrial laser scanning for standardized forest inventories. In: International Archives of Photogrammetry, Remote Sensing and Spatial Information Sciences 36, pp. 192-197.

Vosselman, G., Maas, H. G. (Eds.), 2010. Airborne and terrestrial laser scanning. Whittles Publishing, Dunbeath, United Kingdom.

Walter, L., 2010. Processing of Terrestrial Laser Scanning data with GIS applications, Msc Thesis, Jagiellonian University, Kraków, Paris Lodron University of Salzburg.
Warnecke, L., Nanni, R. V., Nedovic-Budic, Z., Stiteler, W., 2002. Remote Sensing and Geographic Information Technology in the Nation's 50 Forestry Organisations. GeoManagement Associates Inc., Syracuse, New York, USA.

Watt, P.J., Donoghue, D.N.M., Dunford, R.W., 2003. Forest parameter extraction using terrestrial laser scanning. In: Proceeding of the ScandLaser Scientific Workshop on Airborne Laser Scanning of Forests, pp. 2-4. 